\title{
Pengukuran Nilai Gap Layanan Tata Usaha Pascasarjana Unpar Dengan Metode Servqual
}

\author{
Ronaldo Rottie \\ Program Pascasarjana, Magister Teknik Industri, Universitas Katolik Parahyangan \\ Jl. Merdeka No.30, Bandung 40117 \\ Email: aldorottie@gmail.com
}

\begin{abstract}
Kualitas layanan yang diberikan Tata Usaha Pascasarjana Unpar menjadi suatu hal yang penting, karena kebutuhan dari para konsumen yakni mahasiswa pascasarjana yang beraneka ragam sehubungan dengan informasi perkuliahan, administrasi dah hal lainnya. Untuk itu dilakukan penelitian untuk dapat mengetahui kualitas pelayanan berdasarkan peniliaian konsumen terhadap faktor-faktor yang mempengaruhi kualitas pelayanan serta memberikan rekomendasi untuk perbaikan sesuai prioritas. Metode yang digunakan adalah Metode SERVQUAL dengan menilai gap (rentang) antara persepsi konsumen mengenai layanan yang akan diterimanya dan harapan mengenai layanan yang akan diterimanya. Gap dari metode SERVQUAL kemudia akan digunakan sebagai performansi saat ini. Penentuan rekomendasi perbaikan dapat dilakukan dengan menghitung keseluruhan gap (gap 1 sd gap 5) dan Anteceden. Dari hasil pengukuran didapatkan nilai gap 5 sebesar -1.15 , gap 1 sebesar 0 , gap 2 sebesar 7, gap 3 sebesar 2.23 dan gap 4 sebesar 2.17 dengan antesedenya masing-masing untuk antecedents gap 1 sebesar
\end{abstract}

3.75, gap 2 sebesar 3.5, gap 3 sebesar 3.667 dan gap 4 sebesar 4.25

Kata kunci-Kualitas layanan; Gap; Anteceden; SERVQUAL

\section{PENDAHULUAN}

Tata Usaha Pascasarjana Unpar Bandung merupakan salah satu pendukung dalam upaya peningkatan layanan dalam kesatuan Program Pascasarjana Unpar. Dengan adanya Tata Usaha maka segala bentuk kegiatan administrasi di Program Pascasarjana boleh terlaksana dengan baik.

Kualitas pelayanan yang diberikan oleh Tata Usaha Universitas Katolik Parahyangan menjadi suatu hal yang penting, karena kebutuhan dari para konsumen yakni mahasiswa program pascasarjana Unpar yang beraneka ragam sehubungan dengan informasi perkuliahan, administrasi dan hal lainnya. Hal ini terkadang menjadi hal yang sensitif mengingat usia dari para mahasiswa program pascasarjana yang bervariatif dan dengan usia produktif. Selain itu, latar belakang yang berbeda-beda juga membuat pemenuhan kebutuhan akan informasi dan cara pelayanan yang tepat harus dapat diwujudkan oleh pihak Tata Usaha. Berdasarkan pengamatan maka ingin diteliti seberapa baik, tingkat kualitas pelayanan yang diberikan oleh pihak Tata Usaha Pascasarjana Universitas Katolik Parahyangan. Hal ini menjadi suatu langkah awal yang dapat dilakukan agar program pascasarjana keseluruhan dapat menjadi lebih baik dalam pandangan konsumen, karena pelayanan Tata Usaha pun merupakan salah satu elemen yang penting dalam menunjang proses dalam perkuliahan. Oleh karena itu, penelitian ini dilakukan untuk mengetahui tingkat kualitas pelayanan berdasarkan penilaian konsumen (dalam hal ini, para mahasiswa program pascasarjana Unpar) terhadap faktor-faktor yang mempengaruhi kualitas pelayanan dan memberikan usulan untuk perbaikan sesuai prioritas. Perbaikan diharapkan dapat meningkatkan kualitas pelayanan dari Tata Usaha program pascasarjana Unpar.

Metode SERVQUAL digunakan untuk mengukur kualitas pelayanan Tata Usaha program pascasarjana Unpar saat ini. Kualitas pelayanan dinilai berdasarkan gap (rentang) antara persepsi konsumen mengenai layanan yang akan diterimanya dan harapan konsumen mengenai layanan yang akan diterimanya (Zeithaml, 1990). Gap dari metode SERVQUAL kemudian akan digunakan sebagai performansi dari Tata Usaha program pascasarjana UNPAR saat ini. Penentuan usulan perbaikan dapat dilakukan dengan menghitung keseluruhan gap (dari gap 1 s.d. gap 5). Namun pada laporan kali ini akan dibahas terlebih dahulu untuk pengukuran gap 5 (perbedaan persepsi dan harapan dari konsumen akan suatu pelayanan yang diinginkan).

\section{Metode Penelitian}

Jumlah populasi mahasiswa seluruh Pascasarjana Unpar adalah 556 mahasiswa. Jadi yang akan dijadikan sampel menurut rumusan Slovin (dalam Riduwan 2005) adalah $\mathrm{n}=$ $\mathrm{N} / \mathrm{N}(\mathrm{d}) 2+1$ dimana yang akan dijadikan sampel penelitian berjumlah 85 .

Dalam penentuan atribut penelitian, peneliti menentukan atribut-atribut yang ada pada dimensi SERVQUAL berdasarkan studi literatur dan kemudian memilih beberapa atribut yang berhubungan dengan layanan Tata Usaha Program Pascasarjana UNPAR. Dari hasil penggabungan ini didapatkan 22 atribut yang mengukur 5 dimensi kualitas jasa, yaitu: reliability, responsiveness, assurance, empathy, dan tangible.

Kemudian di buat kuesioner pendahuluan yang terdiri dari: profil responden, kuesioner persepsi dan harapan konsumen, kuesioner mengenai penilaian kepentingan tiap atribut oleh pihak manajemen, dan kuesioner antecedent untuk mengukur 
persepsi kualitas layanan. Jadi untuk kuisoner terbagi dalam 2 bagian yaitu untuk konsumen bertujuan untuk mengukur nilai persespsi dan harapan konsumen dan untuk manajemen bertujuan untuk mengukur tingkat performansi dari pihak manajemen apakah sesuai dengan standar yang ada. Kuisoner yang pertama disebarkan ke mahasiswa dan yang kedua disebarkan ke pimpinan dan karyawan Tata Usaha. Dan penyebaran kuisoner dilakukan dengan convenience sampling.

Data yang dikumpulkan kemudian di uji realibilitasnya. Kemudian data diolah menggunakan metode SERVQUAL. Dari hasil pengolahan data dilakukan analysis untuk memperoleh gambaran bagaimana nilai gap 1- 5 dan melihat antecedent gap 1-4 agar dapat diinterpretasikan terhadap nilainilai gap tersebut. Dengan pengolahan data menggunakan Excel 2013 dan SPSS 20.

\section{HASIL DAN PEMBAHASAN}

\subsection{Identifikasi Atribut}

Dilakukan penentuan atribut-atribut sebagai suatu kriteria penilaian. Atribut-atribut didasarkan ke-5 dimensi SERVQUAL, yakni tangibility, reliability, responsiveness, assurance dan empathy. Total untuk atribut pengukuran berjumlah 22 atribut. Atribut- atribut tersebut dapat adalah sebagai berikut.

TABEL 1. ATRIBUt-ATRIibUt LAYANANAN TATA USAHA

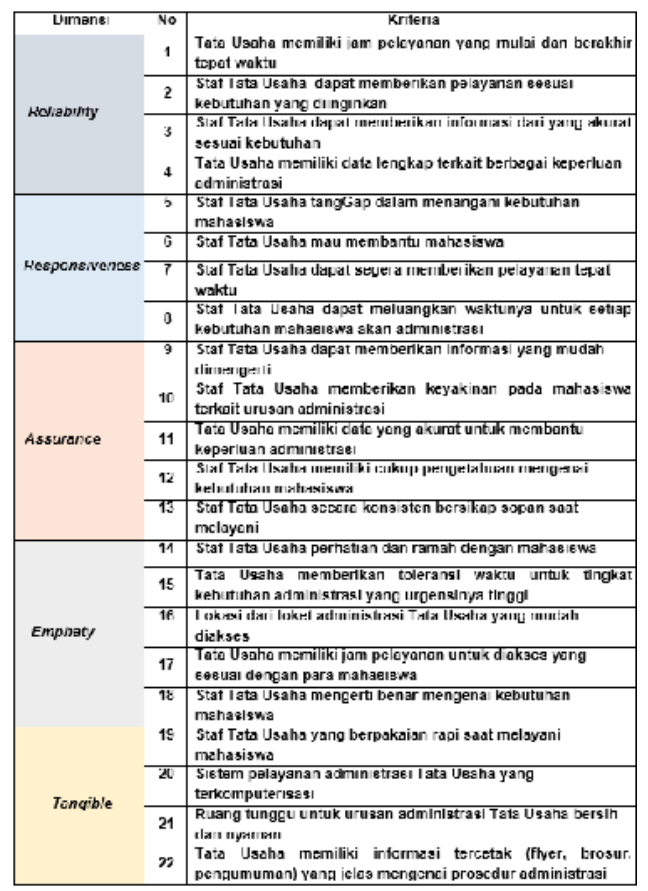

Setelah ditentukan sejumlah atribut sebagai indicator pengukuran selanjutnya adalah penyusunan instrument pengukuran nilai gap. Dan pengumpulan data dilakukan melalui kuisoner agar lebih efisien. Dan untuk pengukuran terdiri dari 5 instrumen pengukuran:

\section{a. Kuisoner Ekspektasi Konsumen (gap 5)}
b. Kuisoner Persepsi Konsimen (gap 5)
c. Kuisoner Persepsi Manajemen (gap 1 \&gap 2)
d. Kuisoner Persepsi Para Karyawan.
e. Kusiner Persepsi Bagian Marketing.
f. Kuisoner Anteseden dari gap 1 \& 2 serta gap 3 \& 4.

\subsection{Penyebaran Kuisoner}

Sebelum melakukan penyebaran kuisoner kepada responden yang berhubungan dengan layanan jumlah sampel responden yang akan dimintai penilaian. Sampel yang digunakan adalah sampel menurut rumusan Slovin (dalam Riduwan 2005) adalah $\mathrm{n}=\mathrm{N} / \mathrm{N}(\mathrm{d}) 2+1$ dimana yang akan dijadikan sampel penelitian berjumlah 85 responden. Dan pengambilan samplenya dilakukan teknik convenience sampling. Untuk bagian pertama dan ketiga berisi nilai harapan dan ersepsi dari responden dari skala 1 s.d 7 terhadap ke 22 atribut dan dikelompokkan berdasarkan dimensi SERVQUAL. Sementara bagian kedua yang merupakan pembobogan penilaian konsumen dengan nilai total ke 5 pertanyaan yang mewakili dimensi SERVQUAL adalah 100. Peneliti melakukan pengecekan dalam memberikan penilaian oleh responden karena dimungkinkan terjadi kekeliruan dalam pengisian tersebut sehingga dapat dilakukan konfirmasi lagi atau dilakukan normalisasi data. Pembobotan tersebut tetap berlaku, karena yang terpenting adalah bagaimana membandingkan kepentingan suatu dimensi dengan dimensi lain.

\subsection{Uji Validitas \& Realibilitas}

Setalah diadapatkan data dari proses penyebaran kuisoner kemudian dilakukan pengujian terhadap ke 85 data dengan menggunakan tools SPSS 20. Dan pengujian dilakukan terhadap dua kuisoner yaitu kuisoner bagian satu untuk harapan konsumen dan kuisoner bagian III untuk performansi layanan. Untuk hasil pengujian kuisoner bagian I setelah dilakukan pengolahan dengn SPSS maka didapatkan output sebagai berikut:

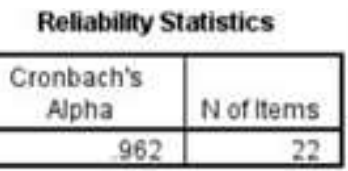

Gambar 1. Hasil uji cronbach's alpha kuisoner bagian I

Dari hasil pengujian nilai $\alpha=0.962$ dibandingkan dengan nilai pada table dengan tingkat kepercayaan $95 \% \quad \alpha=0,312$ oleh karena nilainya lebih besar dari table sehingga signifikan atau reliable. Hal ini berarti bahwa kuisoner sudah dapat mengukur kualitas layanan dan responden konsisten dalam menjawab 
pertanyaan yang sama. Demikian juga hal yang sama untuk kuisoner bagian III:

Reliability Statistics

\begin{tabular}{|c|r|}
\hline $\begin{array}{c}\text { Cronbach's } \\
\text { Alpha }\end{array}$ & N of Items \\
\hline .929 & 22 \\
\hline
\end{tabular}

Gambar 2. Hasil uji cronbach's alpha kuisoner bagian III

Dari hasil dapat dilihat bahwa nilainya hampir sama dengan kuisoner bagian I dan dapat disimpulkan bahwa kuisoner reliable dan dapat dipakai untuk mengukur kualitas layanan.

\subsection{Pengukuran Nilai Gap dan Interpretasi hasil}

Perhitungan nilai SERVQUAL Score gap 5 terlebih dahulu dilakukan. Dengan langkah- langkah sebagai berikut:

1. Mengumpulkan penilaian responden untuk setiap atribut ke dalam 5 dimensi SERVQUAL.

2. Menghitung nilai SERVQUAL Score SERVQUAL Score $=$ Perception Score - Expectation Score

3. Merata-rata nilai setiap atribut dalam satu dimensi masing-masing responden dan diperoleh lima nilai yang mewakili untuk tiap dimensi SERVQUAL.

4. Selanjutnya mengalihkan nilai rata-rata masingmasing dimensi tersebut dengan presentase pembobotan yang diperoleh dari bagian kedua. Persentase didapatkan dengan membagi nilai dengan angka 100. Dan menghasilkan skor SERVQUAL Terbobot.

5. Menjumlahkan skor SERVQUAL Terbobot setiap responden lalu merata- rata jumlah skor SERVQUAL Terbobot tersebut sehingga menghasilkan nilai gap 5 .

Dari hasil pengolahan data dengan Excel 2013 didapatkan nilai gap 5 adalah -1.15 .

Dapat dilihat dari bab sebelumnya bahwa nolai yang berkontribusi besar adalah atribut- atribut dimensi empathy, responsiveness, realibility, assurance, dan tangible. Semua nilai yang negative menunjukkan pelayanan Tata Usaha program pascasarjana UNPAR saat ini belum memuaskan dan dibutuhkan perbaikan. Namun penerpan perbaikan akan lebih baik disesuaikan menurut prioritas.
Tabel 2. Perhitungan gap 5

\begin{tabular}{|c|c|c|c|}
\hline Dimensi & $\begin{array}{r}\text { Rata- } \\
\text { Rata } \\
\text { Skor } \\
\text { Terbob } \\
\text { ot }\end{array}$ & $\begin{array}{c}\text { Persentas } \\
\text { e }\end{array}$ & Rangking \\
\hline Tangible & $-0,16$ & $14,11 \%$ & 5 \\
\hline Reliability & $-0,21$ & $18,45 \%$ & 3 \\
\hline Responsiveness & $-0,28$ & $24,20 \%$ & 2 \\
\hline Assurance & $-0,19$ & $17,01 \%$ & 4 \\
\hline Empathy & $-0,30$ & $26,24 \%$ & 1 \\
\hline Total & $-\mathbf{1 , 1 5}$ & $\mathbf{1 0 0 \%}$ & \\
\hline
\end{tabular}

Dari dimensi tangible meliputi hal-hal fisik seperti keadaan Tata Usaha dilihat dari ruangan yang bersih,system yang terkomputerisasi, serta memiliki informasi tercetak yang jelas dari Tata Usaha tidak terlalu buruk. Sementara dimensi empathy yang memiliki gap terbesar diantara yang lain sehingga menunjukkan bahwa belum bias memberikan pelayanan yang memuaskan kepada konsumen. Kemudian setelah didapatkan hasil gap 5 maka dicari juga nilai gap 1-4. Dan masing-masing hasil pengukuran didapatkan hasil sebagai berikut:

TABEL 3. PERHITUNGAN GAP 1

\begin{tabular}{|r|l|}
\hline KETERANGAN & Nilai \\
\hline Persepsi Manajer & 6,16 \\
\hline Ekspektasi Konsumen & 6,16 \\
\hline Nilai Gap 1 & 0,00 \\
\hline
\end{tabular}

Dari hasil perhitungan gap 1 yang mengindikasikan tidak ada gap antara persepsi manajer dengan ekspektasi konsumen. Pihak manajemen Tata Usaha Program Pascasarjana UNPAR telah memahami dengan tepat apa yang sebenarnya menjadi keinginan konsumen akan layanan dari Tata Usaha. Bila dikaitkan dengan nilai gap 5 yang bernilai negate maka dapat diduga ada permasalahan didalamnya.

TABel 4. PERhitungan GAP 2

\begin{tabular}{|c|c|c|c|c|c|}
\hline \multirow{2}{*}{ Res } & T & $\mathbf{R}$ & $\mathbf{R}$ & $\mathbf{A}$ & $\mathbf{E}$ \\
\cline { 2 - 6 } & 1 & 2 & 3 & 4 & 5 \\
\hline 1 & 0 & 0 & 0 & 0 & 0 \\
\hline \multicolumn{3}{|c|}{ Rata-Rata } & \multicolumn{3}{|c|}{0} \\
\hline
\end{tabular}

Prosiding Seminar Nasional TEKNOIN 2014 ISBN 978-602-14272-1-7 


\section{Nilai Gap 2}

Dari hasil penrhitungan gap 2 dan setelah dilakukan konfirmasi dengan pihak manajemen yang memberikan penilaian, memang tidak ada suatu stander yang diterapkan secara spesifik untuk kelima pernyataan mengenai spesifikasi layanan Tata Usaha Program Pascasarjana Unpar.

Oleh karenanya hal tersebut akan menjadi masalah yang perlu diberikan solusi perbaikan. Nilai gap ini adalah nilai tertinggi maka fokus dari pemberian usulan dapat diarahkan pada permasalahan ini. Dan ketika telah dilakukan perhitungan anteseden nanti dapat ditentukan akar permasalahan yang lebih diprioritaskan.

TABEL 5. PERHITUNGAN GAP 3

\begin{tabular}{|c|c|c|c|c|c|}
\hline \multirow[b]{2}{*}{ Res } & $\mathbf{T}$ & $\mathbf{R}$ & $\mathbf{R}$ & A & $\mathbf{E}$ \\
\hline & 1 & 2 & 3 & 4 & 5 \\
\hline 1 & 0 & 5 & 5 & 6 & 6 \\
\hline 2 & 7 & 3 & 2 & 4 & 5 \\
\hline 3 & 6 & 5 & 5 & 6 & 4 \\
\hline 4 & 5 & 3 & 4 & 4 & 5 \\
\hline 5 & 6 & 6 & 6 & 6 & 6 \\
\hline \multirow[t]{2}{*}{6} & 5 & 4 & 4 & 4 & 6 \\
\hline & 4,8 & 4,3 & 4,3 & 5 & 5,3 \\
\hline \multicolumn{4}{|c|}{ Rata-Rata } & \multicolumn{2}{|c|}{4,77} \\
\hline \multicolumn{4}{|c|}{ Nilai Gan 3} & \multicolumn{2}{|c|}{2,23} \\
\hline
\end{tabular}

Dari hasil perhitungan dapat dilihat bahwa dari nilai yang ada ternyata relative jauh dari yang diharapkan. Karena nilai ini cukup besar sehingga dapat juga diberikan usulan terkait adanya permasalahan dalam pelaksanaan pelayanan oleh pihak staf yang berhubungan langsung dengan konsumen. Fokus usulan dapat diarahkan lebih spesifik setelah dilakukan analisis terhadap akar permasalahan melalui perhitungan antesedennya

TABel 6. PERHitungan GaP 4

\begin{tabular}{|c|c|c|c|c|c|}
\hline \multirow{2}{*}{ Res } & T & R & R & A & E \\
\cline { 2 - 6 } & 1 & 2 & 3 & 4 & 5 \\
\hline $\mathbf{1}$ & 0 & 5 & 5 & 6 & 6 \\
\hline $\mathbf{2}$ & 7 & 3 & 3 & 4 & 5 \\
\hline $\mathbf{3}$ & 6 & 5 & 4 & 5 & 4 \\
\hline $\mathbf{4}$ & 5 & 3 & 4 & 4 & 5 \\
\hline $\mathbf{5}$ & 6 & 6 & 6 & 6 & 6 \\
\hline $\mathbf{6}$ & 5 & 5 & 5 & 6 & 5 \\
\hline & 4,8 & 4,5 & 4,5 & 5,2 & 5,2 \\
\hline \multicolumn{5}{|c|}{ Rata-Rata } & \multicolumn{2}{|c|}{4,83} \\
\hline \multicolumn{5}{|c|}{ Nilai Gap 4 } & \multicolumn{2}{c|}{2,17} \\
\hline
\end{tabular}

Dari hasil yang diperoleh yang relative lebih kecil disbanding nilai gap 3 menunjukkan adanya permasalahan antara pelaksanaan realisasi janji dari pihak penyedia jasa layanan dengan apa yang sebenarnya diterima konsumen

\subsection{Pengukuran dan Interpretasi Anteseden Gap 1-4}

Anteseden adalah akar masalah yang menyebabkan suatu gap besar. Pertama dihitung dulu Anteseden 1 dan 2 yang ditujukan untuk mengukur sejauh mana usaha dari layanan Tata Usaha dalam menerapkan secara empiris faktor-faktor dalam atribut pertanyaan. Atribut pertanyaan yang dimaksud berjumlah 20 pertanyaan, yang dikembangkan berdasarkan informasi yang diperoleh dari penelitian kualitatif yang dilakukan sebelumnya oleh Parasuraman. Dan dari pengolahan data dari kuisoner didapatkan antesden 1 dan 2 kemudian anteseden 3 dan 4

TABEL 7. PENGUKURAN ANTESEDEN 1 DAN 2

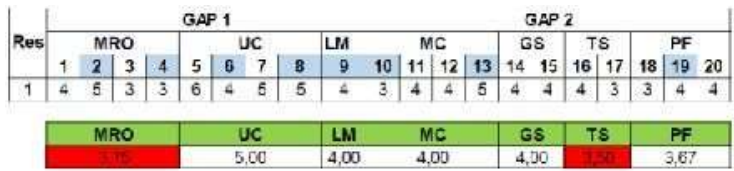

Dari hasil table 7 analisis dari nilai anteseden gap 1 dapat disimpulkan bahwa anteseden yang membuat nilai gap 1 negatif adalah kurangnya orientasi dari bagian yang berfungsu sebagai marketing layanan Tata Usaha. Sedangkah dari hasil analisis anteseden gap 2 dengan nilai anteseden paling kecil adalah standarisasi dari pelaksanaan layanan yang seharusnya bagi para mahasiswa sebagai konsumen dari Tata Usaha.

TABEL 8. PENGUKURAN ANTESEDEN 3 DAN 4

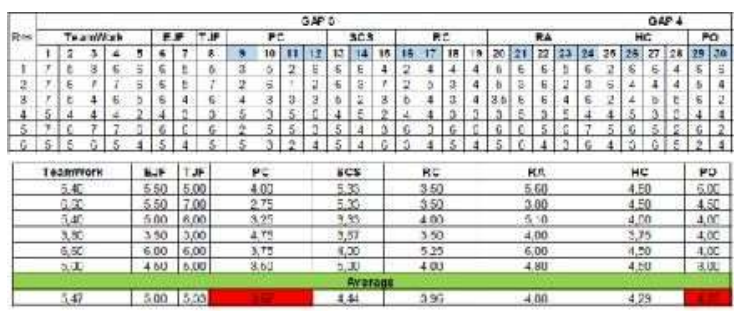

Dari hasil table 8 anteseden gap 3 dapat disimpulkan bahwa kemungkinan bahwa apa yang disampaikan pihak manajemen untuk suatu layanan Tata Usaha seharusnya kurang dapat ditangkap dengan baik oleh karyawan, sehingga diperlukan adanya fungsi control. Sedangkan unruk anteseden gap 4 berarti ada kecenderungan dari bagian marketing yang terlalu memberikan suatu spesifikasi layanan

yang belum tentu dapat diwujudkan sebagaimana mestinya, sehingga konsumen merasa kecewa ketika menerima layanan pada kenyataanya. 


\subsection{Rekomendasi Perbaikan}

Setelah mengetahui dari masing-masing gap, serta penelusuran akar permasalahan melalui perhitungan anteseden, selanjutnya akan diberikan rekomendasi untuk mengurangi atau bahkan mengilangkan gap yang terjadi antara provider dan konsumen.

Rekomendasi atau usulan perbaikan yang akan diberikan diprioritaskan berdasarkan nilai gap yang tertinggi. Hal ini karena, kondisi tersebutlah yang menyebabkan ekspektasi konsumen tidak sesuai dengan yang mereka terima. Karena gap tertinggi ada pada permasalahan manajemen dengan nilai gap $2=7$. Permasalahan ini terkait perihal dimensi- dimensi pengukuran kualitas layanan ServQual yang belum memiliki standarisasi dalam pelaksanaan layanan dalam proses bisnis Tata Usaha.

Sementara itu, dapat dilihat dari nilai anteseden untuk masing-masing gap, guna menelusuri akar permasalahan. Untuk gap 4 yang bernilai 4,25, permasalahan untuk bagian janji marketing ke konsumen tersebut dapat diabaikan untuk masalah perbaikan. Hal ini karena nilai tersebut lebih dari 4 yang dapat dikatakan sebagai standar.

Perbaikan lebih difokuskan pada hal-hal yang menyebabkan gap 2. Setelah dilihat lebih jauh, permasalahannya pun tetap konsisten yakni mengenai standarisasi pekerjaan untuk menyeragamkan pelayanan dari Tata Usaha Program Pascasarjana Unpar. Sehubungan dengan kuisioner yang disebarkan untuk penilaian gap 2 (ketersediaan standar spesifikasi layanan) serta gap 5 (mengenai persepsi dan ekspektasi konsumen), dapat ditentukan usulan perbaikan yang meliputi ke lima dimensi.

Dari rekap gap 5, gap yang paling tinggi yakni sebesar 0.30 terdapat pada bagian Empathy. Dari kuisioner dapat dilihat perihal yang ditanyakan berkaitan dengan perhatian dan kepedulian dari pihak Tata Usaha akan kebutuhan dari pihak mahasiswa terkait kemudahan memperoleh informasi. Selain itu melalui Tabel III.1 dapat dilihat sejumlah atribut layanan dimensi Empathy yang dapat dijadikan fokus pemberian usulan yang dapat diterapkan untuk mengatasi hal tersebut ialah

a. Mewajibkan seluruh staf kesekretariatan untuk selalu siap sedia melayani setiap tamu (mahasiswa) yang memasukin ruangan Tata Usaha dengan ramah. Misalnya dengan cara mengucapkan salam, mempersilahkan duduk dan segera menanyakan kebutuhan/tujuan dari para tamu ke Tata Usaha.

b. Sehubungan dengan jam pelayanan, hendaknya selain mencantumkan jam istirahat dari Layanan Tata Usaha pada pintu depan ruangan.

c. Pemberian training ataupun briefing berkala kepada staf kesekretariatan sebagai salah satu bentuk penyamarataan informasi. Hal ini guna mengantisipasi ketidaktahuan dari para staf kesekretariatan mengenai apa yang menjadi kebutuhan/ditanyakan dari pihak konsumen, karena akan menimbulkan perasaan tidak puas bagi konsumen dan kesan bahwa staf tidak memiliki pemahaman yang cukup.

d. Selain itu, usulan perihal masalah empathy lainnya ialah dengan bersikap memberikan toleransi kepada mahasiswa, untuk sekedar memperoleh informasi atau memproses hal yang dibutuhkannya lebih awal ataupun melebihi jam operasional. Dalam arti jika terdapat sesuatu yang masih ingin ditanyakan atau memperoleh layanan pada 16.00 kurang, staf mengusahakan untuk memproses dan bukan malah menyuruh konsumen kembali kemudian hari. Tentunya untuk urusan- urusan yang dapat diselesaikan dalam waktu singkat. Hal ini akan sangat membantu dan menimbulkan kesan positif dari konsumen.

e. Untuk urusan yang lama ataupun belum dapat dipastikan kapan selesainya, staf dapat menawarkan untuk mencatat kontak person (nama \& nomer telepon) dari yang bersangkutan untuk diberi kabar selanjutnya, sehubungan urusan yang ditinggalkan untuk diproses apabila sudah selesai. Atau dapat juga segera memberitahukan kontak Tata Usaha Pascasarjana dan siapa yang dapat dikontak untuk memperoleh informasi lanjutan akan urusan yang ingin dilakukan oleh konsumen. Hal ini akan sangat membantu bagi konsumen, karena tidak harus bolak- balik atau lama menunggu untuk mengetahui kapan urusan/perihal administrasi yang dibutuhkannya telah selesai.

f. Sehubungan dengan informasi lainnya yang hendak diketahui oleh konsumen/mahasiswa, para staf dapat menghimbau agar mereka membuka halaman website dari Program Pascasarjana UNPAR terlebih dahulu setiap ingin memperoleh informasi di kemudian hari. Seperti misalnya tanggal pendaftaran ulang, tanggal pengajuan draft thesis terakhir, dan pengumuman-pengumuman lainnya. Hal ini tentunya akan memudahkan pihak konsumen untuk memahami terlebih dahulu gambaran mengenai kebutuhannya. Informasi tersebut dapat dikolaborasikan juga dengan student portal yang telah dimiliki oleh setiap mahasiswa. Tentunya dari pihak Tata Usaha, juga harus secara konsisten mempersiapkan informasi dan di postingkan sesegera mungkin.

\section{SIMPULAN}

Dari hasil penelitian yang dilakukan, dapat disimpulkan beberapa hal sebagai berikut:

1. Dari hasil perhitungan kualitas Layanan Tata Usaha Program Pascasarjana Unpar dengan menggunakan metode Servqual, maka dihasilkan nilai gap kualitas pelayanan yaitu: 
a. Nilai gap 5 untuk perbedaan antara apa yang dirasakan dan diharapkan oleh pengunjung secara keseluruhan sebesar -1.15

b. Nilai gap 1 yang merupakan perbedaan antara persepsi manajemen terhadap harapan pengunjung sebesar 0

c. Nilai gap 2 yang menggambarkan perbedaan antara persepsi manajemen terhadap harapan pengunjung dengan standar kerja yang ada sebesar

d. Nilai gap 3 yaitu nilai yang menggambarkan kamampuan staf dalam melaksanakan spesifikasi layanan sebesar 2,23

e. Nilai gap 4 merupakan nilai yang menggambarkan perbedaan antara kualitas layanan dengan apa yang dijanjikan sebesar 2,17

2. Dari hasil pengolahan data juga didapat anteseden yang mengakibatkan adanya nilai gap pada kualitas Layanan Tata Usaha Program Pascasarjana Unpar adalah sebagai berikut:

a. Anteseden penyebab nilai gap 1 adalah kurangnya orientasi bagian marketing.

b. Anteseden penyebab nilai gap 2 adalah belum adanya standarisasi tugas.

c. Anteseden penyebab nilai gap 3 adalah kurangnya kontrol persepsi manajemen dan staf.

d. Anteseden penyebab nilai gap 4 adalah kecenderungan untuk menjanjikan sesuatu secara berlebihan.

\section{DAFTAR PUSTAKA}

[1] Zeithaml, V.A, Parasuraman, A. And Berry, L.L. 1990, Delivering quality service: balancing customer perceptions and expectations, New York: The Free Press.

[2] Zeithaml, V. A., Bitner, M. J., \& Gremler, D. D. 2006, Services marketing: integrating customer focus across the firm, New York: McGraw Hill

[3] Gozhali. 2005, Pengujian SPSS, p 41-42. Riduwan, (2006), Rumus dan Data dalam

[4] Aplikasi Statistik, Alfabeta, Semarang. 